Trace Metal Speciation in Brackish Water Using Diffusive Gradients in Thin Films and Ultrafiltration: Comparison of Techniques.

Jerry Forsberg, Ralf Dahlqvist, Johan Gelting-Nyström and Johan Ingri 



\section{Trace Metal Speciation in Brackish Water Using Diffusive Gradients in Thin Films and Ultrafiltration: Comparison of Techniques}

\author{
JERRY FORSBERG, ${ }^{*}, \dagger$ RALF \\ D A H L Q V S T,, , $\|$ JOHAN \\ GELTING-NYSTRÖM, ${ }^{\dagger}$ AND JOHAN INGRI ${ }^{\dagger}$ \\ Division of Applied Geology, Luleå University of \\ Technology, 97187 Luleå, Sweden, Department of \\ Geology and Geochemistry, Stockholm University, \\ 10691 Stockholm, Sweden, Laboratory for Isotope \\ Geology, Swedish Museum of Natural History, Box 50007, \\ 10405 Stockholm, Sweden, and Department of Earth Sciences, \\ University of Oxford, Parks Road, Oxford OX1 3PR, UK
}

Diffusive gradients in thin films (DGT) and ultrafiltration were used to measure trace metal concentrations in the Baltic Sea. The results provide the first comparison of these two fundamentally different speciation methods for trace metals. $\mathrm{Cd}, \mathrm{Cu}, \mathrm{Mn}, \mathrm{Ni}$, and $\mathrm{Zn}$ were measured at two sites with different total trace metal concentrations. DGT units prepared with APA-gel as diffusive layer and Chelex 100 resin as binding agent were used throughout the study. The ultrafiltration was performed with Millipore Prep/Scale modules with cutoffs of 1 and $10 \mathrm{kDa}$. Concentration levels of $\mathrm{Mn}, \mathrm{Zn}$, and Cd measured by DGT agreed with the concentrations measured in $1 \mathrm{kDa}$ ultrafiltered samples. For $\mathrm{Cu}$ and $\mathrm{Ni}$ the ultrafiltered concentrations exceeded the DGT-labile concentrations. The ability of DGT to preconcentrate metals was found to be an analytical advantage compared with ultrafiltration. DGT appears to be a good alternative to $1 \mathrm{kDa}$ ultrafiltration for measurement of truly dissolved $\mathrm{Mn}, \mathrm{Cd}$, and $\mathrm{Zn}$ in the Baltic Sea.

\section{Introduction}

Distribution, mobility, and toxicity of metals in natural waters are strongly related to their aqueous speciation (1). The biological response of an organism depends not simply on total concentrations but on the activities of the metal ions and their complexes, and on the concentration of labile metal species in solution $(2,3)$. To understand the behavior of an aqueous element and the transformation between chemical forms there is a need for reliable methods that enable measurements of specific fractions of metals.

Ultrafiltration has frequently been used to study speciation of metals in natural waters (e.g., 4, 5). In a recent study, Ingri et al. (6) used cross-flow ultrafiltration technique to determine the size distribution of trace metals and organic carbon in the Baltic Sea. Various evaluations of ultrafiltration techniques have been performed $(7,8)$. Two cross-flow ultrafiltration

\footnotetext{
* Corresponding author phone: +46 920 491931; fax: +46 920 91399; e-mail: jerry.forsberg@ltu.se.

${ }^{\dagger}$ Luleå University of Technology.

* Stockholm University.

$\$$ Swedish Museum of Natural History.

" Currently affiliated with University of Oxford.
}

systems were optimized by Larsson et al. (9) for Baltic Sea surface waters. Some disadvantages are, however, associated with ultrafiltration. The procedure is complicated and demands a rigorous handling protocol for satisfactory results. The laboratory-based filtration process implies sampling and storage of water, which may trigger aggregation and oxidation of metals and result in a change in metal speciation $(10,11)$. Laxen and Chandler (12) found a change in metal speciation in water stored for more than $2 \mathrm{~h}$ between sampling and filtration. Since ultrafiltration is based on grab samples, extensive sampling is necessary if correct average concentrations or temporal variations are to be measured (13), particularly in dynamic waters such as coastal or estuarine waters where metal concentrations may fluctuate extensively. If sampling frequency is low, the measurements may represent a temporary increase or decrease in concentration level instead of the average metal concentration. Ultrafiltration is also an expensive and time-consuming procedure.

A possible alternative or complement to ultrafiltration is the emerging technique of diffusive gradients in thin films (DGT) introduced by Davison and Zhang (14). DGT has been used for trace metal speciation in natural waters (e.g., 15, 16) and provides an in situ measurement of labile metal species, which prevents problems with speciation changes associated with sampling and storage. DGT accumulates metals in proportion to time and produces a mean concentration over the chosen deployment period. The pre-concentration ability is an important quality in waters with extremely low dissolved metal concentrations. DGT is also a cheap, time-saving, and easy-to-use method. In several studies, DGT has been compared to other speciation methods in different types of natural waters. It has been used together with membrane filtration in estuarine waters (13) and compared to competitive ligand exchange followed by voltammetric measurements for measurement of the speciation of $\mathrm{Cu}$ in coastal marine waters (CLE-ACSV) (17), Cu and $\mathrm{Zn}$ in streamwater (CLE-DPASV or CLE-DPCSV) (18), and speciation of Cu, Zn, $\mathrm{Ni}, \mathrm{Cd}, \mathrm{Pb}$, and $\mathrm{Mn}$ in eutrophic lake water (CLE-DPCSV) (16). DGT has also been used in conjunction with dialysis to study speciation of trace metals in lake water (19).

The aim of this study was to compare in situ DGT measurements of trace metals with concentrations measured in $1 \mathrm{kDa}$ ultrafiltered water. Both techniques were simultaneously used in the Baltic Sea at two sampling points with different salinity and total trace metal concentrations (Table 1). The first point, Ekhagen $\left(59^{\circ} 23 \mathrm{~N}, 18^{\circ} 04 \mathrm{E}\right)$, is a low-salinity coastal bay in the vicinity of Stockholm, and the second point is Landsort ( $\left.58^{\circ} 35 \mathrm{~N}, 18^{\circ} 14 \mathrm{E}\right), 40 \mathrm{~km}$ off the Swedish coast in the open Baltic Sea. Sampling was performed in Ekhagen 6 times in 2003, and in Landsort 10 times in 2004. This study provides the first comparison of these two fundamentally different techniques for speciation of trace metals.

\section{Materials and Methods}

Diffusive Gradients in Thin Films (DGT). Standard pistontype DGT units (20) were used throughout this study. The units were prepared as described previously (21) with an APA-gel ( $15 \%$ acrylamide, $0.3 \%$ patented agarose-derived cross-linker) as a diffusive layer, a Chelex 100 resin (Naform, 200-400 mesh) as a binding agent, and a $0.22 \mu \mathrm{m}$ cellulose nitrate membrane filter as a protective outer layer.

Calculations were performed as explained elsewhere (20). With Fick's first law of diffusion and known diffusion coefficient of metal ions within the diffusive gel, the concentration of metal in the bulk waters can be determined 
TABLE 1. Mean Values of Salinity $(\%)$ and Total Metal Concentrations ${ }^{a}$ at Ekhagen and Landsort during Sampling Periods, $n=6$ for Ekhagen, $n=13$ for Landsort

\begin{tabular}{|c|c|c|c|c|c|c|c|c|c|c|c|c|}
\hline & salinity & Ca & Mg & K & $\mathrm{Na}$ & $\mathbf{S}$ & $\mathrm{Fe}$ & Cd & Cu & Mn & $\mathrm{Ni}$ & $\mathrm{Zn}$ \\
\hline Ekhagen & 3.3 & 1.28 & 4.53 & 0.857 & 39.0 & 2.48 & 589 & 0.223 & 33.2 & 224 & 32.9 & 52.1 \\
\hline Landsort & 6.3 & 2.30 & 9.18 & 1.81 & 80.3 & 5.02 & 29.5 & 0.186 & 8.66 & 30.6 & 11.8 & 5.84 \\
\hline
\end{tabular}

from the measured mass of metal accumulated in the resin according to eq 1 .

$$
C=\frac{M \Delta g}{D A \mathrm{t}}
$$

$C$ is the concentration of metal in solution, $M$ is the mass of metal accumulated in the resin, $\Delta g$ is the thickness of hydrogel and membrane filter, $D$ is the diffusion coefficient of the metal ion within the gel, $A$ is the exposure area, and $t$ is the deployment time. Diffusion coefficients provided by DGT Research Ltd. (22) were used for the average water temperatures calculated from in situ temperature measurements every second hour during the deployment periods. The hydrogel thicknesses were $0.75 \pm 0.02 \mathrm{~mm}$ at Ekhagen and $0.77 \pm 0.02 \mathrm{~mm}$ at Landsort. Membrane filter thickness was $0.13 \mathrm{~mm}$ for all DGT units and exposed diffusion area was $3.14 \mathrm{~cm}^{2}$. The elution factor was assumed to be 0.8 for all metals in this study (20). Considering the turbulent marine environment, the diffusive boundary layer (DBL) was assumed to be negligible.

The DGT units were assembled under clean conditions and stored in clean plastic bags at $4{ }^{\circ} \mathrm{C}$. All equipment was washed in $0.1 \mathrm{M} \mathrm{HNO}_{3}$ and rinsed in MilliQ water prior to use. Powder-free disposable gloves were worn during all handling.

In Ekhagen the mean amount and the standard deviations of the blanks $(n=5)$ for each element were (in ng per disc) $3.87 \pm 1.46$ for $\mathrm{Zn}, 1.17 \pm 0.77$ for $\mathrm{Cu}, 0.35 \pm 0.22$ for $\mathrm{Mn}$, and $0.12 \pm 0.06$ for Ni. The percentage masses of metal in the blanks compared to the amount accumulated in the field devices were $2 \%$ for $\mathrm{Zn}, 3 \%$ for $\mathrm{Cu}$, and less than $1 \%$ for $\mathrm{Mn}$ and Ni. Measured masses in blanks from Landsort $(n=10)$ were (in ng per disk) $4.65 \pm 2.44$ for $\mathrm{Zn}, 1.51 \pm 0.71$ for $\mathrm{Cu}$, $0.73 \pm 0.37$ for $\mathrm{Mn}, 0.42 \pm 0.30$ for $\mathrm{Ni}$, and $0.028 \pm 0.028$ for $\mathrm{Cd}$. The percentage masses of metal in the blanks compared to the amount accumulated in the field devices were $10 \%$ for $\mathrm{Zn}, 9 \%$ for $\mathrm{Cu}, 2 \%$ for $\mathrm{Cd}$, and $1 \%$ for $\mathrm{Mn}$ and $\mathrm{Ni}$. The masses of trace metals in these control blanks were used to correct the masses extracted from the devices deployed in the field.

Ultrafiltration. The ultrafiltration system used in this study was a MilliPore Prep/Scale system. Two Prep/Scale Spiral Wound TFF-6 modules were used with manufacturerspecified cutoffs of 1 and $10 \mathrm{kDa}$. For both modules the filter membrane area was $0.54 \mathrm{~m}^{2}$ and the filter material was regenerated cellulose. A Watson Marlow peristaltic baseplate pump was connected to the system.

The sampled water in Ekhagen was pre-filtered through a $0.22 \mu \mathrm{m}$ membrane filter before ultrafiltration, starting with the $10 \mathrm{kDa}$ filter. During the filtration, the permeate $(<10$ $\mathrm{kDa})$ was collected in an acid-cleaned plastic container. Colloidal material $(>10 \mathrm{kDa})$ was retained in the retentate. The collected permeate $(<10 \mathrm{kDa})$ was filtered again, this time through the $1 \mathrm{kDa}$ filter. Material between 1 and $10 \mathrm{kDa}$ was retained in the retentate and the permeate was collected in a new container. Samples were collected for analysis from $0.22 \mu \mathrm{m}, 10 \mathrm{kDa}$, and $1 \mathrm{kDa}$ permeate and from $10 \mathrm{kDa}$ and $1 \mathrm{kDa}$ retentate. At Landsort permeate from the $0.22 \mu \mathrm{m}$ membrane filter was directly filtered through the $1 \mathrm{kDa}$ Prep/ Scale module. Samples were collected for analysis from 0.22 $\mu \mathrm{m}$ and $1 \mathrm{kDa}$ permeate and from $1 \mathrm{kDa}$ retentate.

\section{TABLE 2. Mean Recoveries for Ultrafiltration ${ }^{a}$}

\begin{tabular}{lrrrrr} 
& Mn & Ni & Cu & Zn & Cd \\
Ekhagen $(10 \mathrm{kDa})$ & 88 & 90 & 88 & 89 & \\
Ekhagen $(1 \mathrm{kDa})$ & 91 & 74 & 81 & 66 & \\
Landsort $(1 \mathrm{kDa})$ & 96 & 73 & 94 & 73 & 78 \\
\multicolumn{2}{l}{ a Ekhagen $(n=6)$, Landsort $(n=13)}$.
\end{tabular}

Concentration factors (CF) in Ekhagen were between 16 and 24 for the $10 \mathrm{kDa}$ filter, and between 11 and 14 for the $1 \mathrm{kDa}$ filter. Cross-flow ratios (CFR) (retentate flow/permeate flow) were $>20$ for the $10 \mathrm{kDa}$ filter and $>80$ for the $1 \mathrm{kDa}$ filter. At Landsort, concentration factors were between 16 and 22 and cross-flow ratios were $>60$ for the $1 \mathrm{kDa}$ filter. $\mathrm{CF}$ and CFR were calculated as described previously (23). Mean recoveries for each metal are presented in Table 2. The recoveries for Cd in Ekhagen are left out of Table 2, because almost all values for Cd in Ekhagen were below the detection limit.

Before every new sampling occasion and after every filtration the filters were rinsed with MilliQ water and solutions of $\mathrm{NaOH}$ and $\mathrm{HCl}$, according to a procedure described by Ingri et al. (23).

Field Work. Ekhagen. The sampling was done from a 40-m-long wooden pier in the Ekhagen Bay. Three replicate DGT devices were deployed for approximately 2 weeks in 6 deployment periods between April 2 and June 2, 2003. The units were suspended with plastic rope from a buoy to $4 \mathrm{~m}$ depth. A StowAway TidbiT temperature logger was connected to the DGT device to record temperatures every second hour during the deployment. The recovered DGT units were thoroughly rinsed with MQ water on the deployment site and then placed in clean, airtight plastic bags. On every deployment occasion 1-3 DGT units were chosen as control blanks. These devices were not deployed in the water column.

On 6 occasions between March 18 and June 2, 2003, usually at the start and end of the DGT deployments, water was collected at the sampling site for membrane filtration and ultrafiltration in laboratory. An all plastic Flojet diaphragm pump (ITT industries, flow rate $\sim 5 \mathrm{~L} / \mathrm{min}$ ) was used to collect approximately $25 \mathrm{~L}$ of water from $4 \mathrm{~m}$ depth in an acidcleaned polyethene (PE) container. The water was immediately transported to the laboratory where the filtering process began within $2 \mathrm{~h}$. Unfiltered water samples for direct analysis were also collected at the sampling point.

Landsort. All sampling was conducted from the ship M/S Fyrbyggaren. DGT units were deployed in duplicate, 10 times, for 2 to 4 weeks, over the period March 10 to September 9, 2004. At $5 \mathrm{~m}$ depth, the DGT units were attached to a rope suspended from a buoy and stretched out with a plasticcovered weight. The buoy was connected to another rope anchored at the bottom. As in Ekhagen, temperature loggers were attached to the DGT devices. The recovered DGT units were, as in Ekhagen, rinsed with MilliQ water and placed in plastic bags. On every sampling occasion two DGT units were assembled but not immersed in the water column. These units were used as blanks.

On 13 occasions between March 10 and September 9, 2004 water was collected at Landsort for filtration and 

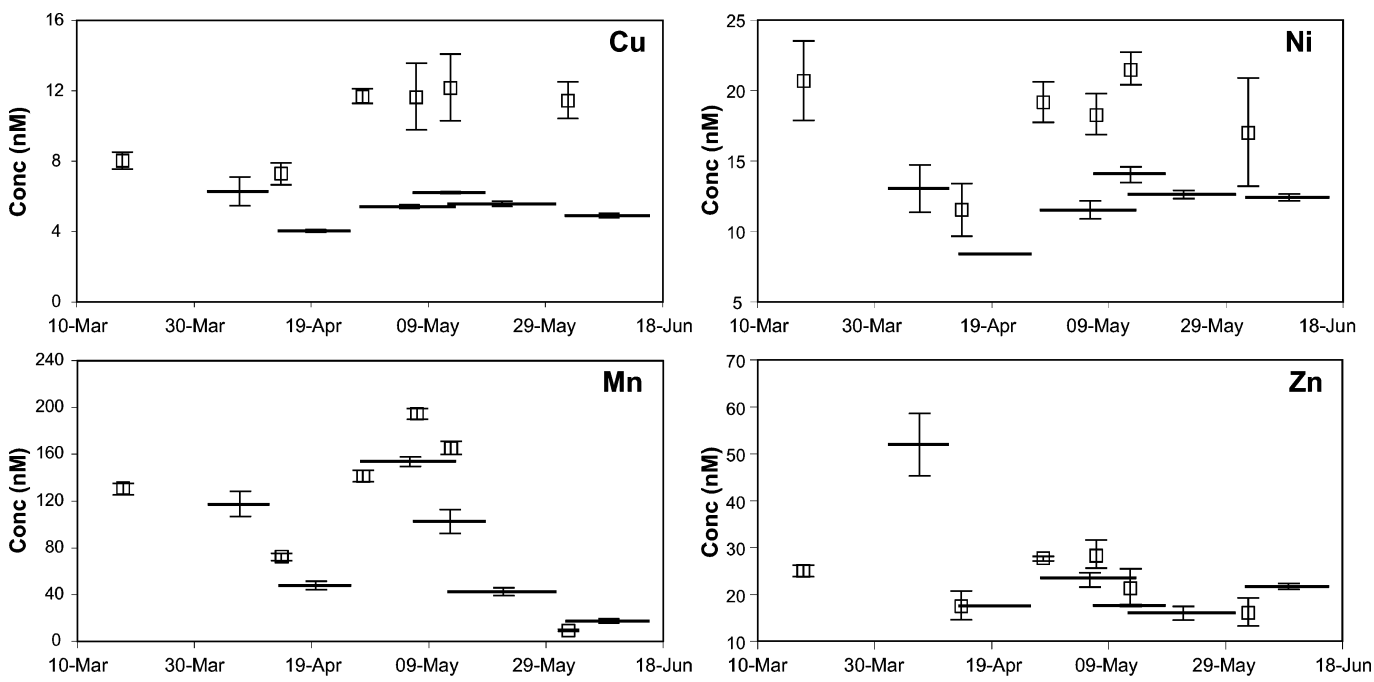

FIGURE 1. Concentrations of $\mathrm{Mn}, \mathrm{Zn}, \mathrm{Cu}$, and $\mathrm{Ni}$ in Ekhagen measured by DGT and ultrafiltration.

unprocessed samples. Water was sampled from $5 \mathrm{~m}$ depth in an acid-cleaned polyethene (PE) container using a Masterflex peristaltic pump. The tubing used to collect water was attached to a flagpole which was mounted to the bow of the ship. The water was therefore sampled approximately $10 \mathrm{~m}$ in front of the ship during slow steaming to avoid contamination derived from the hull. Filtration with $0.22 \mu \mathrm{m}$ membrane filter was performed on board the ship immediately after sampling. The $1 \mathrm{kDa}$ ultrafiltration was conducted in the laboratory within $24 \mathrm{~h}$ after sampling.

Analysis. All analytical work was performed in Class 100 clean room conditions. After sampling and transport to the laboratory, the DGT devices were disassembled and the resin gels were eluted in $5 \mathrm{~mL}$ of $5 \mathrm{M} \mathrm{HNO}_{3}$ (suprapur). Concentrations of elements in DGT eluents, unfiltered samples, 0.22 $\mu \mathrm{m}$ membrane filtrate, and permeate and retentate from the ultrafiltration were determined by ICP-SFMS using an Element (ThermoFinnigan, Bremen, Germany). See Rodushkin and Ruth (24) for operating conditions and measurement parameters. Prior to analysis, water samples were diluted 4-fold with $0.16 \mathrm{M} \mathrm{HNO}_{3}$ (suprapur) in MilliQ water. Matrixinduced signal variations and signal instabilities were corrected for using internal standards ( $25 \mathrm{ppb}$ In and $\mathrm{Tl}$ ) added to samples, blanks, and standards. Quality control was accomplished by regular analyses of in-house control samples.

\section{Results and Discussion}

Measurement Definition. Before the results are presented it is important to emphasize the basic differences between the measurement techniques. DGT measures a flux which is used to calculate an average concentration over the deployment period, and the discrimination of metal species in the gel is based on size and lability. A gel pore size of approximately $5 \mathrm{~nm}$ permits free metal ions, inorganic metal complexes, and small organic metal complexes to diffuse, while particles and large colloids are excluded $(20,25)$. Since the complexes must dissociate in the hydrogel to be measured, only complexes with sufficient dissociation rate will be retained in the resin (20). Kinetically inert species are excluded.

The ultrafiltration is performed in the laboratory and based on a grab sampling approach. The discrimination of metal species by ultrafiltration is based on size. A pore size of $1 \mathrm{kDa}$ equals approximately $2 \mathrm{~nm}$. It should be noted that the pores of a filter with manufacturer-specified cutoff of $1 \mathrm{kDa}$ range between $\sim 0.7$ and $\sim 1.3 \mathrm{kDa}(7)$ and also that the cutoff, in daltons, is a nominal value and that the real cutoff depends on the structure and chemical composition of the metal species present (9). Studies with CFF ultrafilters have shown that a manufacturer-defined cutoff of $1 \mathrm{kDa}$ corresponds to a real cutoff of $2.1-2.5 \mathrm{kDa}(7,9)$. Since a major part of seawater colloids are just above $1 \mathrm{kDa}$ in size (26) it can be expected that the $1 \mathrm{kDa}$ CFF permeate, besides free metal ions, will contain different forms of complexes and colloids. The ultrafiltration will, unlike DGT, not discriminate inert and immobile complexes.

The metal concentrations in $1 \mathrm{kDa}$ ultrafiltered permeate are compared with DGT-labile concentrations in the two sampling points in Figures 1 and 2. DGT results are presented as lines reflecting the deployment period and the ultrafiltered results are shown as points at the time of sampling. The error bars represent the instrumental deviation for ultrafiltered results and the standard deviation of replicate devices, simultaneously deployed, for DGT.

Mn, Zn, Cd. Concentrations of Mn, Zn, and Cd measured by DGT were similar to the concentrations measured in 1 kDa ultrafiltered samples, especially for Mn (Figures 1 and 2). The generally good agreement between the two techniques is likely due to the weak tendency of these metals to form organic complexes. Mn seems to exist predominantly in particulate fractions or in truly dissolved species in Ekhagen (6). Munksgaard and Parry (15) found that almost $100 \%$ of the dissolved Cd is labile in estuarine waters. The agreement between the two techniques is not as evident for $\mathrm{Zn}$ as for $\mathrm{Mn}$ and $\mathrm{Cd}$. Studies have shown that $\mathrm{Zn}$ can be strongly bound in small nonlabile complexes (16). The measured concentrations of $\mathrm{Zn}$ in ultrafiltered water from Landsort were close to the detection limit for some samples, which must be taken into consideration.

$\mathrm{Cu}$, Ni. For $\mathrm{Cu}$ and $\mathrm{Ni}$ the ultrafiltered concentrations clearly exceeded the DGT-labile concentrations (Figures 1 and 2). This indicates the existence of low molecular weight $\mathrm{Cu}$ and $\mathrm{Ni}$ species, small enough to pass through the $1 \mathrm{kDa}$ ultrafilter but not labile enough to be retained in the DGT units. A substantial complexation by organic substances has 

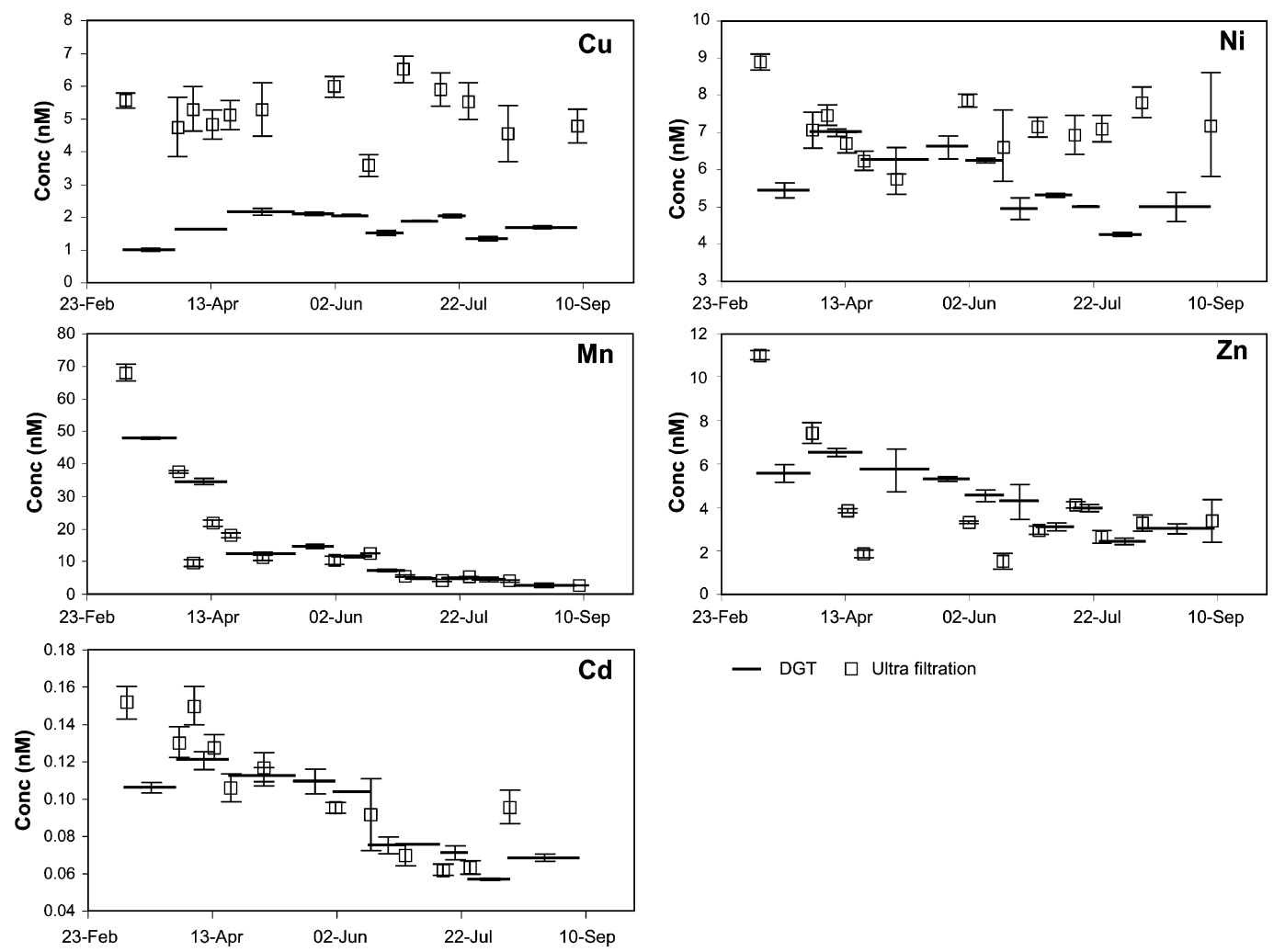

FIGURE 2. Concentrations of $\mathrm{Mn}, \mathrm{Zn}, \mathrm{Cu}, \mathrm{Ni}$, and $\mathrm{Cd}$ in Landsort measured by DGT and ultrafiltration.

been found for $\mathrm{Cu}$ and $\mathrm{Ni}$ in seawater $(17,27-29)$. Ingri et al. (6) found that $35 \%$ of the $\mathrm{Ni}<0.22 \mu \mathrm{m}$ and $54 \%$ of the $\mathrm{Cu}$ $<0.22 \mu \mathrm{m}$ in Ekhagen was in colloidal forms. The organic complexes have diffusion coefficients substantially lower than free metal ions (30). Since diffusion coefficients for free ions are used in this study, the DGT-labile concentrations are probably underestimated, contributing to the difference in concentrations measured by the two methods.

Complexation by simple organic ligands such as nitrilotriacetic acid (NTA) or diglycolic acid (DGA) lowers the diffusion coefficient of trace metals in the gel by approximately $25 \%$, whereas fulvic acid (FA) species will contribute to the mass of metal measured by DGT with approximately $20 \%$ of the sensitivity of uncomplexed metal $(31,32)$. If we use these reduced diffusion coefficents for $\mathrm{Cu}$ and $\mathrm{Ni}$ and assume that $100 \%$ of the concentration measured with DGT is complexed with simple organic ligands we do not reach the concentration measured in the ultrafiltered fraction. Assuming $100 \%$ complexation with FA gives concentrations in the DGT over the observed concentrations in the ultrafiltered fraction. For $\mathrm{Cu}$, a combination of $20 \%$ free metal ions and $80 \% \mathrm{FA}$-species gives the same concentrations in the DGT and ultrafiltered fractions in Landsort. The combination for $\mathrm{Ni}$ is $70 \%$ free metal ions and $30 \% \mathrm{FA}$-species. In Ekhagen the figures are $40 \%$ and $60 \%$ for $\mathrm{Cu}$ and $60 \%$ and $40 \%$ for $\mathrm{Ni}$, respectively.

General Assessment. Both methods have strengths and weaknesses. DGT measures a time-integrated average concentration, while the ultrafiltrated concentrations are based on a single grab sample. The ultrafiltered concentrations can therefore be nonrepresentative for a period of time. On the other hand, if the results are supposed to be compared to unfiltered grab samples or membrane filtrates, the ultrafiltration might render a more direct comparison. A comparison with DGT demands a composite sample comprising several grab samples collected during the DGT deployment period. This was addressed in a study by Dunn et al. (13). The importance of speciation change during transport and storage has been shown in earlier work (12, 19), and a change in metal speciation, during the time between sampling and filtration, cannot be ruled out for water collected for ultrafiltration in this study. The time and money saving factor using DGT is important, especially when sampling is conducted over prolonged time periods. In waters with very low metal concentrations, where analysis of ultrafiltration permeate results in values below detection limits, DGT is useful because of the pre-concentration capability.

\section{Acknowledgments}

This research has been carried out with financial support from the Swedish Research Council, the Norrbotten Research Council, Analytica AB, and the Geological Survey of Sweden (SGU). We thank Analytica AB (Rickard Hernell) for support with analysis, the crew of M/S Fyrbyggaren and the Stockholm Marine Research Center (Leif Lundgren) for support in field, and the Institute of Applied Environmental Research, Stockholm University (Örjan Gustafsson) for letting us use their facilities.

\section{Literature Cited}

(1) Ure, A. M.; Davidson, C. M. In Chemical Speciation in the Environment; Ure, A. M., Davidson, C. M., Eds.; Blackie Academic \& Professional: London, 1995; pp 1-5. 
(2) Morel, F. M. M.; Hering, J. G. Principles and Applications of Aquatic Chemistry; Wiley: New York, 1993.

(3) Hudson, R. J. M.; Morel, F. M. M. Iron transport in marine phytoplankton: Kinetics of cellular and medium coordination reactions. Limnol. Oceanogr. 1990, 35 (5), 1002-1020.

(4) Guo, L.; Santschi, P. H.; Warnken, K. W. Trace metal composition of colloidal organic material in marine environments. Mar. Chem. 2000, 70, 257.

(5) Dahlqvist, R.; Benedetti, M. F.; Andersson, K.; Turner, D.; Larsson, T.; Stolpe, B.; Ingri, J. Association of calcium with colloidal particles and speciation of calcium in the Kalix and Amazon rivers. Geochim. Cosmochim. Acta 2004, 68, 4059.

(6) Ingri, J.; Nordling, S.; Larsson, J.; Ronnegard, J.; Nilsson, N.; Rodushkin, I.; Dahlqvist, R.; Andersson, P.; Gustafsson, O. Size distribution of colloidal trace metals and organic carbon during a coastal bloom in the Baltic Sea. Mar. Chem. 2004, 91, 117.

(7) Wilding, A.; Liu, R.; Zhou, J. L.Validation of cross-flow ultrafiltration for sampling of colloidal particles from aquatic systems. J. Colloid Interface Sci. 2004, 280, 102.

(8) Gueguen, C.; Belin, C.; Dominik, J. Organic colloid separation in contrasting aquatic environments with tangential flow filtration. Water Res. 2002, 36, 1677.

(9) Larsson, J.; Gustafsson, Ö.; Ingri, J. Evaluation and Optimization of Two Complementary Cross-Flow Ultrafiltration Systems toward Isolation of Coastal Surface Water Colloids. Environ. Sci. Technol. 2002, 36, 2236.

(10) Buffle, J.; Leppard, G. G. Characterization of Aquatic Colloids and Macromolecules. 1. Structure and Behavior of Colloidal Material. Environ. Sci. Technol. 1995, 29, 2169.

(11) Buffle, J.; Leppard, G. G. Characterization of Aquatic Colloids and Macromolecules. 2. Key Role of Physical Structures on Analytical Results. Environ. Sci. Technol. 1995, 29, 2176.

(12) Laxen, D. P. H.; Chandler, M. I. Comparison of filtration techniques for size distribution in freshwaters. Anal. Chem. 1982, $54,1350$.

(13) Dunn, R. J. K.; Teasdale, P. R.; Warnken, J.; Schleich, R. R. Evaluation of the Diffusive Gradient in a Thin Film Technique for Monitoring Trace Metal Concentrations in Estuarine Waters. Environ. Sci. Technol. 2003, 37, 2794.

(14) Davison, W.; Zhang, H. In situ speciation measurements of trace components in natural waters using thin-film gels. Nature 1994, 367, 546.

(15) Munksgaard, N. C.; Parry, D. L. Monitoring of labile metals in turbid coastal seawater using diffusive gradients in thin-films. J. Environ. Monit. 2003, 5, 145.

(16) Odzak, N.; Kistler, D.; Xue, H.; Sigg, L. In situ trace metal speciation in a eutrophic lake using the technique of diffusion gradients in thin films (DGT). Aquat. Sci. 2002, 64, 292

(17) Twiss, M. R.; Moffett, J. W. Comparison of Copper Speciation in Coastal Marine Waters Measured Using Analytical Voltammetry and Diffusion Gradient in Thin-Film Techniques. Environ Sci. Technol. 2002, 36, 1061.

(18) Meylan, S.; Odsak, N.; Behra, R.; Sigg, L.Speciation of copper and zinc in natural freshwater: comparison of voltammetric measurements, diffusive gradients in thin films (DGT) and chemical equilibrium models. Anal. Chim. Acta 2004, 510, 91.
(19) Gimpel, J.; Zhang, H.; Davison, W.; Edwards, A. C. In Situ Trace Metal Speciation in Lake Surface Waters Using DGT, Dialysis, and Filtration. Environ. Sci. Technol. 2003, 37, 138.

(20) Zhang, H.; Davison, W. Performance Characteristics of Diffusion Gradients in Thin Films for the in Situ Measurement of Trace Metals in Aqueous Solution. Anal. Chem. 1995, 67, 3391.

(21) Dahlqvist, R.; Zhang, H.; Ingri, J.; Davison, W. Performance of the diffusive gradients in thin films technique for measuring Ca and $\mathrm{Mg}$ in freshwater. Anal. Chim. Acta 2002, 460, 247.

(22) DGT Research Ltd. Practical Guide for Using DGT for Metals in Waters; http://www.dgtresearch.com (accessed August 2005).

(23) Ingri, J.; Widerlund, A.; Land, M.; Gustafsson, Ö.; Andersson, P.; Öhlander, B. Temporal variations in the fractionation of the rare earth elements in a boreal river; the role of colloidal particles. Chem. Geol. 2000, 166, 23.

(24) Rodushkin, I.; Ruth, T. Determination of trace metals in estuarine and sea-water reference materials by high resolution inductively coupled plasma mass spectrometry. J. Anal. Atom. Spectrom. 1997, 12, 1181 .

(25) Zhang, H.; Davison, W. Diffusional characteristics of hydrogels used in DGT and DET techniques. Anal. Chim. Acta 1999, 398, 329.

(26) Guo, L.; Santschi, P. H. Isotopic and elemental characterization of colloidal organic matter from the Chesapeake Bay and Galveston Bay. Mar. Chem. 1997, 59, 1.

(27) Achterberg, E. P.; Van Den Berg, C. M. G. Chemical speciation of chromium and nickel in the western Mediterranean. DeepSea Res. II 1997, 44, 693.

(28) Martino, M.; Turner, A.; Nimmo, M. Distribution, speciation and particle-water interactions of nickel in the Mersey Estuary, UK. Mar. Chem. 2004, 88, 161.

(29) Muller, F. L. L.; Gulin, S. B.; Kalvoy, A. Chemical speciation of copper and zinc in surface waters of the western Black Sea. Mar. Chem. 2001, 76, 233.

(30) Zhang, H.; Davison, W. Direct In Situ Measurements of Labile Inorganic and Organically Bound Metal Species in Synthetic Solutions and Natural Waters Using Diffusive Gradients in Thin Films. Anal. Chem. 2000, 72, 4447.

(31) Scally, S.; Davison, W.; Zhang, H. Diffusion coefficients of metals and metal complexes in hydrogels used in diffusive gradients in thin films. Anal. Chim. Acta 2006, 558, 222.

(32) Unsworth, E.; Warnken, K. W.; Zhang, H.; Davison, W.; Black, F.; Buffle, J.; Cao, J.; Cleven, R. F. M. J.; Galceran, J.; Gunkel, P.; Kalis, E. J. J.; Kistler, D.; Van Leeuwen, H. P.; Noel, S.; Nur, Y.; Odzak, N.; Puy, J.; Van Riemsdijk, W. H.; Sigg, L.; Temminghoff, E. J. M.; Tercier-Waeber, M.-L.; Toepperwien, S.; Town, R. M.; Weng, L. P.; Xue, H. Model predictions of metal speciation in fresh water measured by in situ techniques. Environ. Sci. Technol. 2006, 40, 1942.

Received for review January 13, 2006. Revised manuscript received April 7, 2006. Accepted April 11, 2006.

ES0600781 